\title{
MASSA DE FORRAGEM E VALOR NUTRITIVO DE GRAMÍNEAS PERENES DE INVERNO NO PLANALTO NORTE CATARINENSE
}

\author{
FORAGE MASS AND NUTRITIONAL VALUE OF WINTER PERENNIAL \\ GRASSES IN THE NORTH PLATEAU OF SANTA CATARINA STATE, BRAZIL
}

\author{
Ana Lúcia HANISCH${ }^{1}$ \\ Itamar GISLON ${ }^{2}$
}

\begin{abstract}
RESUMO
Este trabalho teve o objetivo de avaliar, nas condições edafoclimáticas do Planalto Norte Catarinense (PNC), sete genótipos de gramíneas perenes de inverno com potencial para uso em sistemas de produção animal: Bromus auleticus, Dactylis glomerata, Phalaris aquatica, Festuca arundinacea cv Epagri $312 \mathrm{com} 0$ e $40 \%$ de fungo endofítico (F.E.), Festuca arundinacea cv 'au Triumph' e Arrhenatherum elatius, nos anos de 2006 e 2007. O delineamento experimental foi de blocos completos casualizados, com quatro repetições. Avaliou-se a massa de forragem (MF) e a cobertura do solo (\%CS). No ano de 2006 foi avaliada a composição bromatológica na primavera. Todos os genótipos apresentaram teores de proteína bruta acima de $20 \mathrm{dag} \mathrm{kg}^{-1} \mathrm{e}$ digestibilidade in vitro da matéria orgânica acima de $65 \mathrm{dag} \mathrm{kg}^{-1}$. Em relação à MF, houve interação significativa entre genótipos e estações nos dois anos avaliados. Em 2006, todos os genótipos apresentaram a maior produção durante a primavera e em 2007 os valores de MF diferiram entre inverno e primavera apenas para Bromus e Arrhenatherum. Houve interação significativa entre genótipos e épocas de avaliação para \%CS sendo que todos os genótipos reduziram a \%CS no $2^{\circ}$ ano. Na média dos dois anos, os valores de MF variaram de 3.309 a $5.237 \mathrm{~kg} \mathrm{MS} \mathrm{ha}^{-1}$, respectivamente para Bromus e Arrhenatherum. Com base nos resultados observados o genótipo Phalaris aquatica apresentou comportamento anual e os genótipos Arrhenatherum elatius, Festuca arundinacea cv Epagri 312 (0\% F.E.) e Festuca arundinacea cv au Triumph apresentaram potencial de uso para a região.

Palavras-chave: cevadilha-serrana; aveia perene; faláris; dátilo; pastagem.
\end{abstract}

\begin{abstract}
This experiment was carried out to evaluate the potential of seven genotypes of perennial grasses of winter for use in animal systems: Bromus auleticus, Dactylis glomerata, Phalaris aquatica, Festuca arundinacea cv Epagri $312(0$ and $40 \%$ of Endophytic fungi), Festuca arundinacea cv 'au Triumph' and Arrhenatherum elatius, in the climatic conditions of North Plateau of Santa Catarina State, Brazil, during two consecutive years of 2006 and 2007. Treatments were arranged in a randomized complete block design with four replicates. Were evaluated forage mass of genotypes and ground cover (\%). In the year of 2006 the crude protein (CP) and digestibility in vitro of organic matter (DIVOM) were evaluated in the spring. All the genotypes presented contents of CP above of 20 dag kg-1 and DIVOM above of 65 dag kg-1. There was significant interaction $(p<0,05)$ between genotypes and season for forage mass. In 2006 the forage mass of the genotypes was greater in the spring. In 2007, with exception of the Bromus and Arrhenatherum no have difference in the forage mass among spring and winter. There was significant interaction $(p<0,05)$ between genotypes and ground cover $(\%)$. In the second year all the genotypes reduced the ground cover (\%). On the average of two years, the yield potential of DM ranged from 3,3 to $5,2 \mathrm{t} \mathrm{ha}^{-1}$ respectively for Bromus and Arrhenatherum. The results would suggest that the genotype Phalaris aquatica have annual cycle and the genotypes Arrhenatherum elatius, Festuca arundinacea cv Epagri 312 (0\% Endophytic fungi) and Festuca arundinacea cv au Triumph present potential of use for the region.

Key-words: cevadilha-serrana; perennial oats; falaris; dactylo; pasture.
\end{abstract}

\footnotetext{
1 Eng $^{a}$ Agra ${ }^{a}$ M.Sc., Pesquisadora da Empresa de Pesquisa Agropecuária e Extensão Rural de Santa Catarina (EPAGRI) - Estação Experimental de Canoinhas, BR 280, Km 219,5 - Cx. Postal 216, Canoinhas, Santa Catarina, Brasil. CEP: 89460-000. E-mail: analucia@epagri.sc.gov.br Autor para correspondência

${ }^{2}$ Eng. Agr., M.Sc., Empresa de Pesquisa Agropecuária e Extensão Rural de Santa Catarina (EPAGRI) - Escritório Municipal de Joinville/SC, Joinville, Santa Catarina, Brasil. E-mail: igislon@epagri.sc.gov.br
} 
HANISCH, A.L. \& GISLON, I. Massa de forragem e valor nutritivo...

\section{INTRODUÇÃO}

Em Santa Catarina há uma demanda crescente para a identificação de espécies de pastagens perenes que possam atender às necessidades nutricionais dos rebanhos e que sejam adaptadas às condições edafoclimáticas das diferentes regiões. $\mathrm{O}$ foco em pastagens perenes contribui para o desenvolvimento de sistemas de produção que reduzem as práticas de preparo de solos, podem recuperar nutrientes em maiores profundidades do que os cultivos com pastagens anuais, além de restaurar o fluxo de matéria orgânica do solo (Dubeux Júnior. et al., 2006).

$\mathrm{Na}$ região do Planalto Norte Catarinense (PNC) é comum ocorrerem investimentos em espécies forrageiras anuais de inverno como aveia e azevém. No entanto, grande parte das áreas utilizadas com pastagens anuais de inverno são áreas destinadas às culturas anuais de verão (Balbinot Jr. et al., 2008), o que reforça uma situação conhecida como "vazio forrageiro" períodos que ocorrem no início do outono e no início da primavera, quando há uma considerável redução na disponibilidade e na qualidade das pastagens existentes, em especial as de ciclo anual.

Dentre as espécies perenes de inverno já submetidas ao melhoramento genético e introduzidas no Brasil, apenas a festuca (Festuca arundinacea Schreb) tem sido cultivada para a formação de pastagens perenes de inverno e possui boa disponibilidade de sementes comerciais (Rosa et al., 2008; Scheffer-Basso et al., 2002a). Há poucos trabalhos publicados no Brasil sobre o desempenho dos gêneros Dactylis, Phalaris e Arrhenatherum sob corte ou pastejo (Rosa et al., 2008; Flaresso et al., 1997). O gênero Bromus compreende mais de 100 espécies anuais e perenes de gramíneas tipicamente de estação fria distribuídas pelo mundo (Yanaka et al., 2005). Destas, a cevadilha vacariana (Bromus auleticus Trinius), vem sendo objeto de pesquisas em diversas instituições da América do Sul, por apresentar ótimo valor forrageiro, boa capacidade de rebrote e, por ser perene, a possibilidade de fornecer forragem no outono-inverno (SchefferBasso et al., 2005).

Para Pedreira et al. (2005) a adequação entre o suprimento e a demanda de alimentos é um dos pontos de maior importância em sistemas de produção animal, mas a gestão desses sistemas se confronta com a baixa capacidade de previsão e o limitado controle da produtividade e dos estoques de forragem existentes na propriedade. Assim, avaliar a produção de matéria seca das pastagens e a distribuição desta produção ao longo do ano é fundamental para o planejamento dos sistemas de produção animal.

O objetivo deste trabalho foi avaliar o desempenho de sete genótipos de gramíneas perenes de inverno em relação à massa de forragem, composição bromatológica e cobertura do solo nas condições climáticas do PNC, com a finalidade de selecionar genótipos com potencial de uso em sistemas de produção animal.

\section{MATERIAL E MÉTODOS}

O experimento foi conduzido no Campo Experimental Salto do Canoinhas da Estação Experimental da Epagri de Canoinhas, no município de Papanduva, região do Planalto Norte de Santa Catarina, durante os anos de 2006 e 2007. O clima da região é classificado como $\mathrm{Cfb}$, segundo a classificação de Köppen. A área experimental se localiza pelas coordenadas $26^{\circ} 10^{\prime}$ de latitude Sul e $50^{\circ} 23^{\prime}$ de longitude Oeste, com altitude média de $840 \mathrm{~m}$ acima do nível do mar. Nas Figuras 1 e 2 estão apresentados os dados de temperatura e precipitação pluviométrica dos anos de 2006 e 2007.

O solo da área experimental é classificado como Latossolo Vermelho Distrófico (EMBRAPA, 2006) e apresentava na ocasião da implantação do experimento as seguintes características químicas: $340 \mathrm{~g} \mathrm{~kg}^{-1}$ de argila; $\mathrm{pH}$ em água $=5,2 ; \mathrm{pH}$ SMP $=$ 5,$1 ; \mathrm{P}=2,3 \mathrm{mg} \mathrm{dm}^{-3} ; \mathrm{K}=71 \mathrm{mg} \mathrm{dm}^{-3} ; \mathrm{Al}=0,9 \mathrm{cmol}$ $\mathrm{dm}^{-3}$; matéria orgânica $=49 \mathrm{~g} \mathrm{dm}^{-3}$.

$O$ delineamento experimental foi $\mathrm{o}$ de blocos ao acaso com parcelas subdivididas, sendo que os genótipos foram alocados nas parcelas e as estações do ano nas sub-parcelas, com quatro repetições. Os genótipos avaliados foram: cevadilha-serrana (Bromus auleticus) cultivar Seleção Lages; dátilo (Dactylis glomerata) 'Amba'; faláris (Phalaris aquatica) 'Cinquentenário'; festucas (Festuca arundinacea) 'Epagri 312 - Lages' com $40 \%$ do fungo endofítico (F.E.) Acremonium coenophialum; 'Epagri 312 - Lages' com 0\% do F.E. e 'Au Triumph'; aveia-perene (Arrhenatherum elatius) 'Vacaria'. As plantas originais foram obtidas por sementes provenientes do Banco Ativo de Germoplasma da Epagri - Estação Experimental de Lages que vem realizando trabalhos de avaliação e seleção desses materiais há quase uma década.

Os genótipos foram semeados no dia 02 de junho de 2005. O solo não foi calcariado e recebeu adubação de acordo com as recomendações para gramíneas de inverno (Sociedade..., 2004), com a aplicação de $80 \mathrm{~kg} \mathrm{ha}^{-1}$ de $\mathrm{P}_{2} \mathrm{O}_{5}, 80 \mathrm{~kg} \mathrm{ha}^{-1}$ de $\mathrm{K}_{2} \mathrm{O}$ e $40 \mathrm{~kg} \mathrm{ha}^{-1}$ de $\mathrm{N}$ na formulação comercial 5-20-20. As parcelas mediam $4 \times 2,1 \mathrm{~m}$, com área útil de $2,7 \mathrm{~m}^{2}(3 \times 0,90 \mathrm{~m})$. As sementes foram distribuídas em linhas espaçadas em trinta centímetros.

Em março de 2006, todas as parcelas receberam um corte de emparelhamento e trinta dias depois foram iniciados os cortes para avaliação da massa de forragem (MF) que foram realizados a cada 6 semanas no outono-inverno e a cada 4 semanas durante a primavera-verão, perfazendo um total de oito cortes durante o ano $(11 / 04 ; 30 / 05$; 26/07; 28/08; 28/09; 26/10; 23/11, 18/12 e 22/01). Após cada corte, as parcelas receberam $20 \mathrm{~kg} \mathrm{ha}^{-1}$ de $\mathrm{N}$ em cobertura, na forma de uréia.

Para as avaliações de 2007, em março todas as parcelas receberam um corte de 
HANISCH, A.L. \& GISLON, I. Massa de forragem e valor nutritivo...

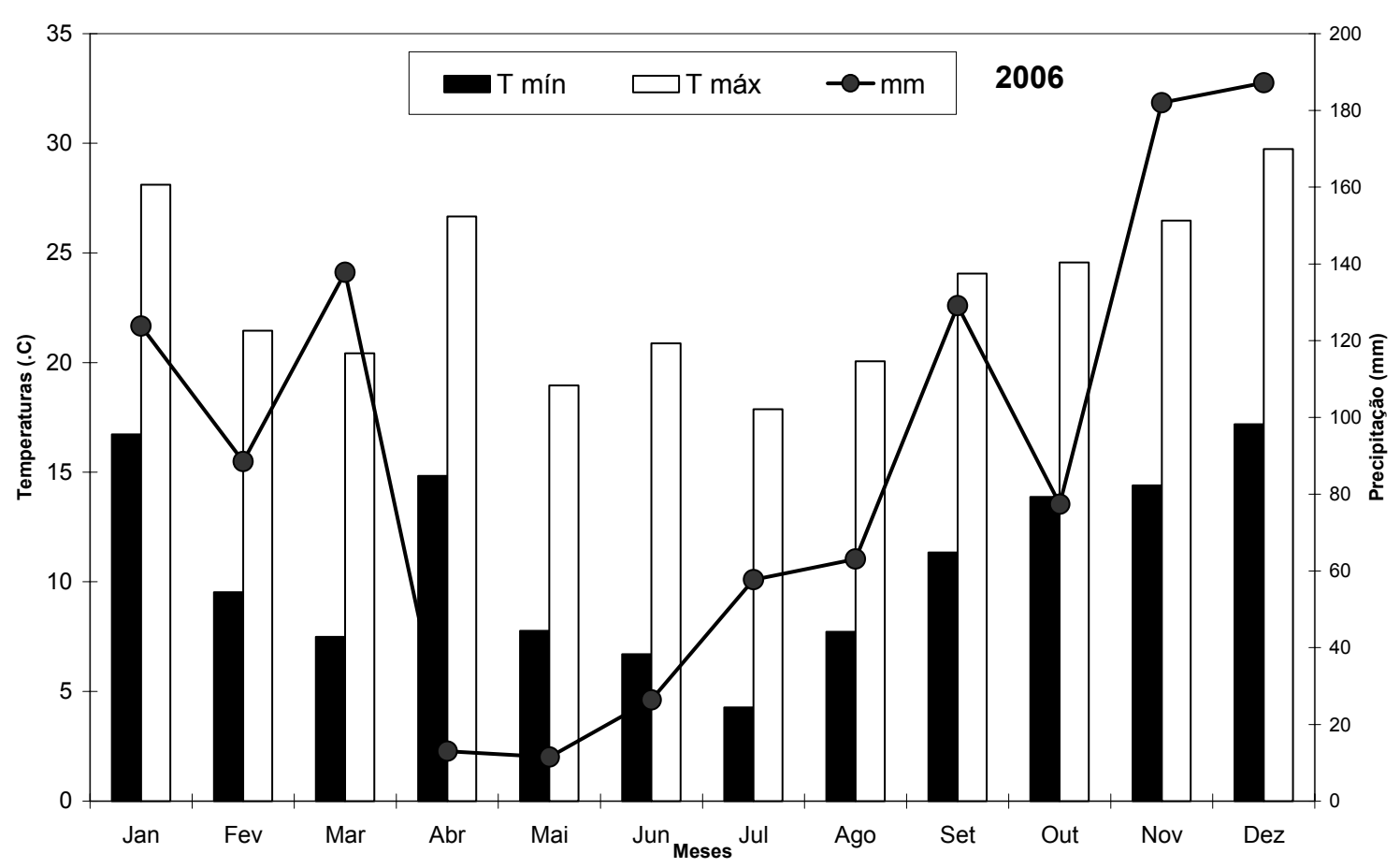

FIGURA 1 - Média das temperaturas mínimas (T mín) e máximas (T máx) e precipitação mensal em milímetros (mm) no ano de 2006. Fonte: EPAGRI/CIRAM

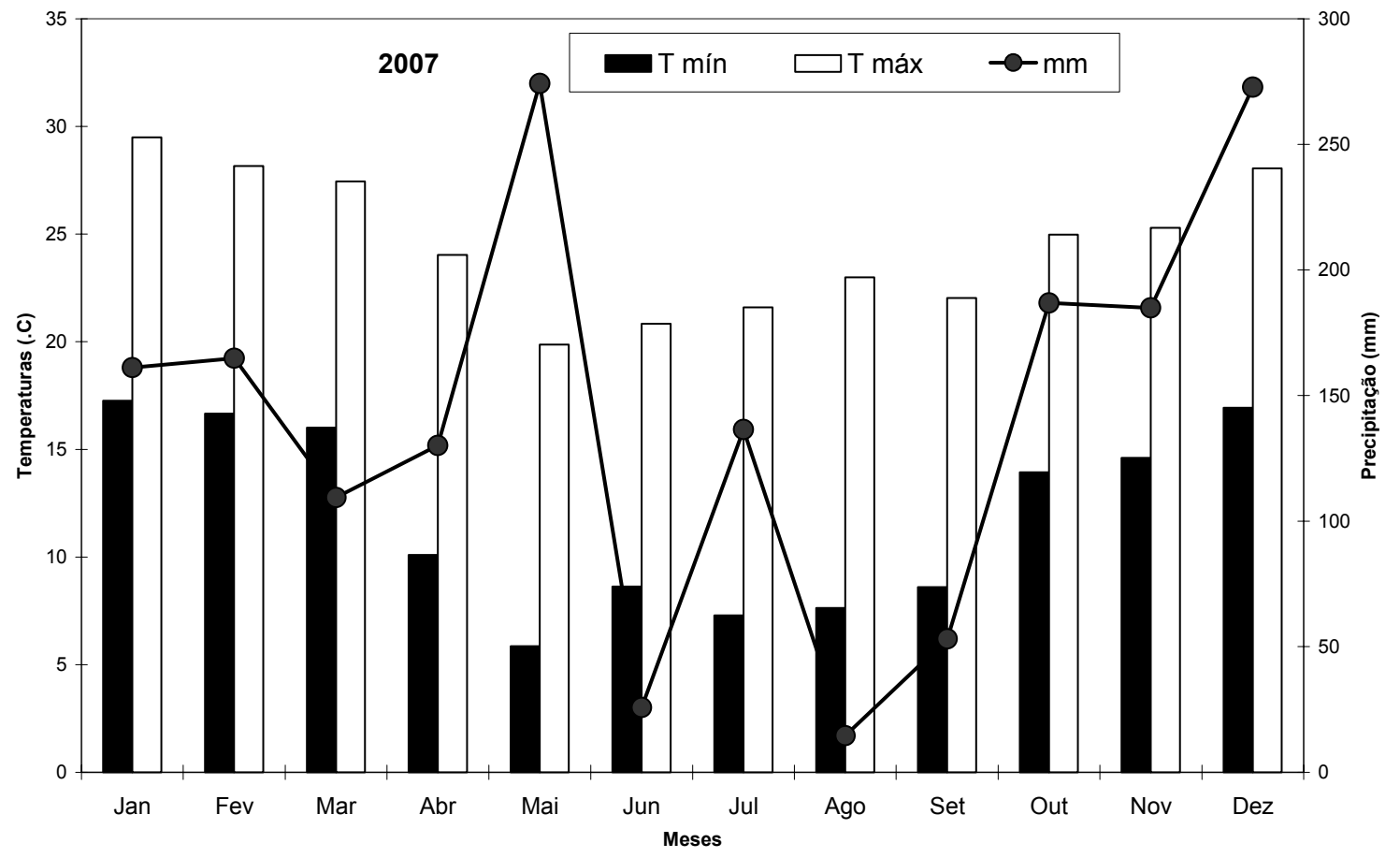

FIGURA 2 - Média das temperaturas mínimas (T mín) e máximas (T máx) e precipitação mensal em milímetros (mm) no ano de 2007. Fonte: EPAGRI/CIRAM 
HANISCH, A.L. \& GISLON, I. Massa de forragem e valor nutritivo...

emparelhamento, uma vez que após o último corte para avaliação do verão 2006/07 realizado em janeiro, as plantas que já haviam sementado, apresentaram um crescimento muito irregular dentro e entre as parcelas. Após o corte de emparelhamento foi realizada adubação de acordo com a recomendação para gramíneas de inverno (Sociedade..., 2004), com a aplicação de $60 \mathrm{~kg} \mathrm{ha}^{-1}$ de $\mathrm{P}_{2} \mathrm{O}_{5}, 60 \mathrm{~kg} \mathrm{ha}^{-1}$ de $\mathrm{K}_{2} \mathrm{O}$ e $40 \mathrm{~kg} \mathrm{ha}^{-1}$ de $\mathrm{N}$, na formulação comercial 5-20-20. O primeiro corte das parcelas ocorreu em julho. A partir deste corte, o próximo ocorreu, após aproximadamente seis semanas e, a seguir aproximadamente cada quatro semanas, perfazendo um total de cinco cortes em 2007 (30/06; 13/09; 15/10; 17/11 e 15/12).

As parcelas foram capinadas sempre que necessário a fim de manter os genótipos livres da competição com invasoras. Para isso, foram realizadas três e cinco capinas, respectivamente, para o primeiro e segundo anos do experimento.

Para estimar a massa de forragem (MF) foram realizados cortes manuais com tesoura de tosquia, na área total útil da parcela $\left(2,7 \mathrm{~m}^{2}\right)$ a uma altura aproximada de $0,10 \mathrm{~m}$ do nível do solo. A pastagem cortada foi pesada para estimativa da MF em $\mathrm{kg} \mathrm{ha}^{-1}$ e em seguida retirada uma sub-amostra para estimar o percentual de MS. Todas as subamostras foram secas em estufas com circulação forçada de ar, com temperaturas de $65^{\circ} \mathrm{C}$ até atingir massa constante. A massa de forragem total da pastagem $\left(\mathrm{kg} \mathrm{ha}^{-1}\right)$ foi estimada pelo somatório da massa de forragem coletada nos cortes, em cada ano.

Para os cortes de primavera de 2006 (setembro e outubro) as sub-amostras de cada genótipo foram reunidas e homogeneizadas. $\mathrm{Na}$ seqüência foram retiradas duas amostras compostas de cada mistura para determinação da composição bromatológica, que foram moídas em peneiras de $1 \mathrm{~mm}$ e encaminhadas para análise dos teores de proteína bruta (PB), fibra bruta (FB), digestibilidade in vitro da matéria orgânica (DIVMO) e nutrientes digestíveis totais (NDT) de acordo com a metodologia de Silva \& Queiroz (2002).

As avaliações da cobertura do solo (\%CS) foram realizadas em três estações em cada ano: verão (janeiro), inverno (junho) e primavera (outubro). A porcentagem de solo coberto foi determinada por estimativas visuais sempre pelo mesmo observador treinado, em área total da parcela (Flaresso et al., 1997; Andrade et al., 2003) e os resultados classificados de 0 a $100 \%$ da CS pela plantas.

Os dados de MF e \%CS foram submetidos à análise de variância com o auxílio do programa estatístico Sisvar (Ferreira, 2000) através do modelo de parcela subdividida no tempo, no qual as cultivares constituíram a parcela principal e as estações do ano as sub-parcelas. Quando constatados efeitos significativos dos tratamentos as médias foram comparadas pelo teste de ScottKnott a $5 \%$ de probabilidade. Para a análise dos dados de \%CS os valores foram transformados pela fórmula arc seno $(x / 100)^{1 / 2}$. Os valores da composição bromatológica não foram submetidos à análise estatística, pois não foram avaliados com repetições.

\section{RESULTADOS E DISCUSSÃO}

Os dados de MF para o primeiro ano, dos sete genótipos avaliados, podem ser observados na Tabela 1. Houve efeito significativo a $5 \%$ para interação genótipo $x$ estações do ano. Todos os genótipos apresentaram valores de MF significativamente maiores na primavera em relação às demais estações do ano e, com exceção da faláris, apresentaram valores de MF semelhantes entre as estações de outono, inverno e verão.

TABELA 1 - Massa de forragem (MF) de sete genótipos de gramíneas perenes de inverno em Canoinhas/SC no ano de 2006

\begin{tabular}{|c|c|c|c|c|}
\hline Genótipos & Outono/06 & Inverno/06 & Primavera/06 & Verão/06-07 \\
\hline Cevadilha & 694,05 c B & 864,23 a B & 2039,12 b A & 835,04 a B \\
\hline Dátilo & 1211,71 c B & 1079,21 a B & 2653,91 a $A$ & 1011,35 a B \\
\hline Faláris & 2146,33 a B & 1501,84 a $C$ & 2811,07 a $A$ & 131,77 b D \\
\hline $\begin{array}{l}\text { Festuca Epagri } 312 \\
\text { 40\% F.E. }\end{array}$ & 1130,79 с B & 1170,64 a B & 3240,81 a $A$ & 1128,11 a B \\
\hline $\begin{array}{l}\text { Festuca Epagri } 3120 \% \\
\text { F.E. }\end{array}$ & 1482,29 b B & 1359,65 a $B$ & 3279,12 a $A$ & 1385,22 a B \\
\hline Festuca au Triumph & $1542,51 \mathrm{~b} B$ & 1359,29 a B & 2707,84 a A & 1151,36 a B \\
\hline Aveia perene & 1183,89 с B & 1394,86 a B & 2837,44 a $A$ & 1470,53 a B \\
\hline C.V. $1(\%)$ & 36,24 & & & \\
\hline C.V. $2(\%)$ & 22,77 & & & \\
\hline
\end{tabular}

Médias seguidas de mesma letra, minúscula na coluna e maiúscula na linha, não diferem entre si pelo teste de Scott-Knott a $5 \%$ de probabilidade. F.E. = fungo endofítico. C.V. = coeficiente de variação. C.V. $1=$ erro da parcela; C.V. $2=$ erro geral. 
A grama faláris apresentou comportamento produtivo diferenciado dos demais, sendo o genótipo com maior MF durante o outono e com a menor MF no verão.

Em 2006, a cevadilha-serrana apresentou o menor valor de MF total $\left(4.382,44 \mathrm{~kg} \mathrm{MS} \mathrm{ha}^{-1}\right)$, seguido pelo dátilo com $5.956 \mathrm{~kg} \mathrm{MS} \mathrm{ha}^{-1}$, enquanto aveia perene, faláris e as três festucas apresentaram valores superiores a $6.500 \mathrm{~kg} \mathrm{MS} \mathrm{ha}$ 1. Rosa et al. (2008) avaliando os mesmos genótipos na região de São Joaquim/SC com altitude de $1.412 \mathrm{~m}$, obtiveram rendimentos semelhantes aos descritos neste trabalho para dáctilo, faláris, as festucas e a aveia perene. Para a cevadilha, esses autores obtiveram valores 5.028 $\mathrm{kg} \mathrm{MS} \mathrm{ha-1}$, superiores aos encontrados neste trabalho, indicando uma possível adaptação desse material às condições de altas altitudes.

No primeiro ano foram realizados 4 cortes na primavera, entre setembro e dezembro, o que significou a obtenção de valores aproximados de $800 \mathrm{~kg} \mathrm{MS} \mathrm{ha}^{-1}$ corte $^{-1}$ para os genótipos mais produtivos, no manejo adotado de cortes a cada 4 semanas. No outono e inverno ocorreu apenas um corte para cada estação. Este é um aspecto importante a se considerar no planejamento forrageiro, pois durante a primavera, nas condições do PNC há diversos genótipos de gramíneas perenes de verão que já estão produzindo (Hanisch \& Dalgallo, 2008; Hanisch \& Gislon, 2008) que podem competir por área nas propriedades. Neste sentido, um aspecto importante na seleção de genótipos de gramíneas perenes de inverno é sua capacidade produtiva no período outono/inverno, onde há uma real escassez forrageira na região.

Os resultados de MF para o ano de 2007 novamente apresentaram efeitos significativos a $5 \%$ para a interação genótipos $x$ estações do ano (Tabela 2). Os valores de MF diferiram entre inverno e primavera apenas para Bromus e Arrhenatherum, enquanto as demais mantiveram valores de massa de forragem semelhantes entre essas duas estações. No verão, com exceção da faláris, todos os genótipos apresentaram produções significativamente menores. Festuca Epagri 312 '40\% F.E'. e faláris diferiram dos demais nas três estações, apresentando valores de MF significativamente menores. No segundo ano de avaliação os cortes para avaliação foram realizados a partir de junho, uma vez que não ocorreu desenvolvimento vegetativo dos genótipos antes do inverno. Este fato está relacionado, em parte, ao excesso de chuvas que ocorreram neste período (Figura 2), que contribuiu para o crescimento excessivo de plantas daninhas nas parcelas, e em parte, aos baixos valores de \%CS dos genótipos observados durante o verão do primeiro ano de avaliação (Tabela 3). Neste ano, foi realizado apenas um corte no inverno, um no verão e três na primavera, onde os genótipos mais produtivos apresentaram em média $350 \mathrm{~kg} \mathrm{MS} \mathrm{ha-1}$ corte $^{-1}$, valores muito abaixo dos observados por Rosa et al. (2008) e aos observados no primeiro ano de avaliação deste experimento.

TABELA 2 - Massa de forragem (MF) de sete genótipos de gramíneas perenes de inverno em Canoinhas/SC no ano de 2007

\begin{tabular}{|c|c|c|c|c|}
\hline Genótipos & Outono/07 & Inverno/07 & Primavera/07 & Verão/07-08 \\
\hline Cevadilha & - & 768,07 c B & 1134,96 a $A$ & 331,72 a $C$ \\
\hline Dátilo & - & 824,41 b A & 1140,99 a $A$ & 342,57 a $B$ \\
\hline Faláris & - & $101,45 \mathrm{~d} A$ & 313,58 c A & 59,11 b A \\
\hline $\begin{array}{l}\text { Festuca Epagri } 312 \\
\text { 40\% F.E. }\end{array}$ & - & 463,76 c A & $733,34 \mathrm{~b} \mathrm{~A}$ & 168,37 b B \\
\hline $\begin{array}{l}\text { Festuca Epagri } 312 \text { 0\% } \\
\text { F.E. }\end{array}$ & - & 1131,03 b A & 974,59 a $A$ & 255,72 a $B$ \\
\hline Festuca au Triumph & - & 1148,30 b A & 1036,02 a $A$ & 323,62 a $B$ \\
\hline Aveia perene & - & 1774,72 a $A$ & 1312,47 a $B$ & 500,00 a $C$ \\
\hline C.V. $1(\%)$ & 40,78 & & & \\
\hline C.V. $2(\%)$ & 31,17 & & & \\
\hline
\end{tabular}

Médias seguidas de mesma letra, minúscula na coluna e maiúscula na linha, não diferem entre si pelo teste de Tukey a $5 \%$ de probabilidade. F.E. = fungo endofítico. C.V. = coeficiente de variação. C.V. 1 = erro da parcela; C.V. $2=$ erro geral.

As festucas Epagri 312 '0\% F.E.' e 'au Triumph' apresentaram no verão valores de MF que corresponderam, respectivamente, a $22 \%$ e $28 \%$ dos valores de MF obtidos no inverno, indicando sua dificuldade de adaptação à elevação da temperatura. Para Sleper \& Bucker (1995) o crescimento dessa espécie é principalmente primaveril, o que em muitas regiões corresponde a quase dois terços do seu crescimento anual, fato que também foi observado neste experimento. 
HANISCH, A.L. \& GISLON, I. Massa de forragem e valor nutritivo...

TABELA 3 - Porcentagem de cobertura do solo (\%CS) de genótipos de gramíneas perenes de inverno em Canoinhas/SC nos anos de 2006/2007.

\begin{tabular}{|c|c|c|c|c|c|c|}
\hline Genótipos & $03 / 01 / 06$ & $06 / 06 / 06$ & $11 / 10 / 06$ & $31 / 01 / 07$ & $25 / 06 / 07$ & $22 / 10 / 07$ \\
\hline Cevadilha & 100 a $A$ & $90 \mathrm{~b} \mathrm{~B}$ & 80 a C & $35 \mathrm{bE}$ & $38 \mathrm{cE}$ & $65 \mathrm{~b} \mathrm{D}$ \\
\hline Dátilo & 100 a $A$ & $92 \mathrm{~b} \mathrm{~A}$ & 57 a B & $40 \mathrm{~b} \mathrm{C}$ & $25 \mathrm{c} \mathrm{C}$ & $60 \mathrm{~b} \mathrm{~B}$ \\
\hline Faláris & 100 a $A$ & 100 a $A$ & $35 \mathrm{~b} \mathrm{~B}$ & $7 \mathrm{c} \mathrm{C}$ & $5 \mathrm{dC}$ & $19 \mathrm{~d} C$ \\
\hline $\begin{array}{l}\text { Festuca Epagri } \\
31240 \% \text { F.E. }\end{array}$ & 100 a $A$ & 100 a $A$ & 72 a B & 55 a B & 30 c C & $45 \mathrm{c} \mathrm{C}$ \\
\hline $\begin{array}{l}\text { Festuca Epagri } \\
3120 \% \text { F.E. }\end{array}$ & 100 a $A$ & 100 a $A$ & 72 a B & 65 a C & $55 \mathrm{~b} \mathrm{C}$ & 77 a B \\
\hline $\begin{array}{l}\text { Festuca } \\
\text { Triumph }\end{array}$ & 100 a $A$ & 100 a $A$ & 67 a B & 70 a B & $65 \mathrm{~b} \mathrm{~B}$ & 75 a B \\
\hline Aveia perene & 100 a $A$ & 100 a $A$ & 77 a B & 75 a B & 75 a B & 80 a B \\
\hline C.V. $1(\%)$ & 9,19 & & & & & \\
\hline C.V. $2(\%)$ & 14,39 & & & & & \\
\hline
\end{tabular}

Médias seguidas de mesma letra, minúsculas nas colunas e maiúsculas nas linhas não diferem entre si pelo teste de ScottKnott a $5 \%$ de probabilidade. F.E. = fungo endofítico. C.V. = coeficiente de variação. C.V. 1 = erro da parcela; C.V. 2 = erro geral.

No segundo ano, apesar da redução de $48 \%$ na MF total em relação ao primeiro ano, a aveia perene apresentou o maior valor entre os genótipos avaliados $(3.587,19 \mathrm{~kg} \mathrm{MS} \mathrm{ha-1)} \mathrm{e} \mathrm{foi} \mathrm{o}$ genótipo mais produtivo no inverno. Por outro lado, o genótipo festuca Epagri 312 '40\% F.E.' apresentou valores consideravelmente baixos de MF (Tabela 2) e de \%CS (Tabela 3), indicando uma baixa adaptação às condições do PNC, com o manejo adotado neste experimento.

Os valores de MF e de \%CS apresentados pela faláris no segundo ano, indicam que esse genótipo não apresentou comportamento produtivo de gramínea perene, podendo ser classificada como de ciclo anual nas condições edafoclimáticas do PNC.

Houve interação significativa (5\%) entre genótipos e épocas de avaliação para a \%CS. Todos os genótipos apresentaram redução da \%CS em relação aos resultados do primeiro ano (Tabela 4). Aveia perene e festucas Epagri 312 '0\% F.E.' e 'au Triumph' mantiveram \% CS superiores a $70 \%$ ao final do segundo ano de avaliação, enquanto os demais genótipos não atingiram esse patamar. Este é um parâmetro importante a ser considerado em relação à persistência desses genótipos quando introduzidos em um sistema de produção. SchefferBasso et al. (2002b) avaliando freqüência e altura de corte em dois genótipos de Bromus auleticus verificou interação entre altura e freqüência de corte para esta espécie, concluindo que sua produção e persistência poderiam ser comprometidas com cortes baixos $(0,05 \mathrm{~m})$ e freqüentes (4 semanas). É possivel que a cevadilha-serrana tivesse apresentado outro comportamento caso os cortes não fossem fixados por tempo, mas por altura de planta. No entanto, para o presente experimento, a característica de baixos valores de cobertura de solo, indica uma não apropriação para sistemas de produção, pois este fato pode demandar um trabalho considerável para manter as áreas de pastagem livres de plantas daninhas, o que, na prática, pode acarretar em desaparecimento da pastagem.

TABELA 4 - Teores de proteína bruta (PB), fibra bruta (FB), digestibilidade in vitro da matéria orgânica (DIVMO) e nutrientes digestíveis totais (NDT) de sete genótipos de gramíneas perenes de inverno durante a primavera. Canoinhas, 2006.

\begin{tabular}{|c|c|c|c|c|}
\hline \multirow[b]{2}{*}{ Genótipos } & PB & FB & DIVMO & NDT \\
\hline & 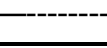 & 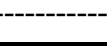 & & \\
\hline Cevadilha & 25,25 & 29,05 & 68 & 63 \\
\hline Dátilo & 22,25 & 25,2 & 66,45 & 60,6 \\
\hline Faláris & 23,6 & 24,1 & 72,8 & 67,5 \\
\hline Festuca Epagri 312 40\% F.E. & 20,65 & 25,9 & 72,6 & 67,15 \\
\hline Festuca Epagri 312 0\% F.E. & 20,45 & 24,45 & 71,9 & 66,55 \\
\hline Festuca au Triumph & 21,85 & 25,25 & 72,7 & 66,8 \\
\hline Aveia perene & 21,7 & 20,75 & 72,6 & 66,55 \\
\hline
\end{tabular}

F.E. = fungo endofítico. 
HANISCH, A.L. \& GISLON, I. Massa de forragem e valor nutritivo...

$\mathrm{Na}$ avaliação da composição bromatológica, todos os genótipos apresentaram teores de PB acima de 20 dag kg ${ }^{-1}$ e DIVMO acima de $65 \mathrm{dag} \mathrm{kg}^{-1}$ (Tabela 4), valores superiores aos obtidos por Scheffer-Basso et al. (2005) que, avaliando os teores de PB de oito populações de Bromus auleticus coletadas em municípios do Rio Grande do Sul, submetidas a cinco cortes, entre março e setembro, obtiveram para o mês de setembro, média de $18,7 \mathrm{dag} \mathrm{kg}^{-1}$ de PB. Oliveira \& Moraes (1993) também avaliando acessos de Bromus auleticus, observaram teores acima de 24 e 17 dag $\mathrm{kg}^{-1}$ de $\mathrm{PB}$, respectivamente para o período de inverno e outono. Neste trabalho, a cevadilhaserrana apresentou teores de PB de 25,25 dag kg-1 nas amostras avaliadas provenientes dos cortes de primavera, indicando a manutenção da qualidade nutricional desta espécie para este período. Costa \& Scheffer-Basso (2003), avaliando valor nutritivo de Festuca arundinacea em clima Cfa, obtiveram teores de 15,38 dag $\mathrm{kg}^{-1}$ de PB em lâminas foliares durante a primavera, valor consideravelmente menor que o observado neste trabalho, o que pode ter sido decorrente dos efeitos da maior temperatura do clima $\mathrm{Cfa}$, em relação ao clima $\mathrm{Cfb}$.

\section{CONCLUSÕES}

Ocorrem variações significativas nos valores de massa de forragem e cobertura do solo entre os sete genótipos de gramíneas perenes de inverno avaliadas nas condições edafoclimáticas do Planalto Norte Catarinense, sendo que nestas condições o genótipo Phalaris aquatica apresentou comportamento anual.

Destacaram-se como promissores para serem avaliados em condições de campo, os genótipos aveia perene, festuca Epagri 312 '0\% F.E.' e festuca 'au Trimph', devido aos maiores valores de massa de forragem nos dois anos de avaliação e à maior \% de cobertura do solo apresentado no segundo ano, o que indica persistência às condições avaliadas.

\section{AGRADECIMENTOS}

À Epagri - Estação Experimental de Lages, em especial ao pesquisador José Lino Rosa por seu inestimável apoio durante a condução do experimento e por seu excelente trabalho com gramíneas perenes de inverno em Santa Catarina, e ao pesquisador Gilcimar Adriano Vogt pelo apoio na análise dos dados.

\section{REFERÊNCIAS}

1. ANDRADE, C. M. S. et al. Desempenho de seis gramíneas solteiras ou consorciadas com o Stylosanthes guianensis cV. Mineirão e eucalipto em sistema silvipastoril. Revista Brasileira de Zootecnia, v. 32, n. 6, p. 1845-1850, 2003 (Supl. 2).

2. BALBINOT JR., A. A. et al. Formas de uso do solo no inverno e sua relação com a infestação de plantas daninhas em milho (Zea mays) cultivado em sucessão. Planta Daninha, v. 26, n. 3, p. 569-576, 2008.

3. COSTA, D. I.; SCHEFFER-BASSO, S. M. Caracterização morfofisiológica e agronômica de Paspalum dilatatum Poir. biótipo Virasoro e Festuca arundinacea Schreb. 1. Desenvolvimento Morfológico. Revista Brasileira de Zootecnia, v. 32, n. 5, p.1054-1060, 2003.

4. DUBEUX JÚNIOR, J. C. B. et al. Fluxo de nutrientes em ecossistemas de pastagens: impactos no ambiente e na produtividade. In: SIMPÓSIO SOBRE MANEJO DA PASTAGEM, 23., 2006, Piracicaba. Anais... Piracicaba: FEALQ, 2006. p. 439-506

5. EMPRESA BRASILEIRA DE PESQUISA AGROPECUÁRIA (EMBRAPA). Sistema Brasileiro de Classificação de Solos. 2. ed. Brasília: EMBRAPA, 2006. 306 p.

6. FERREIRA, D. F. Análises estatísticas por meio do Sisvar para Windows versão 4.0. In: REUNIÃO ANUAL DA REGIÃO BRASILEIRA DA SOCIEDADE INTERNACIONAL DE BIOMETRIA, 45., 2000, São Carlos. Anais... São Carlos: UFSCar, 2000. p. 255-258.

7. FLARESSO, J. A. et al. Gramíneas perenes de inverno para o Alto Vale do Itajaí, Santa Catarina. Agropecuária Catarinense, v. 10, n. 1, p. 24-26, 1997.

8. HANISCH, A. L.; GISLON, I. Avaliação da produtividade e persistência de cultivares de Paspalum notatum no Sul do Brasil In: REUNIÃO ANUAL DA SOCIEDADE BRASILEIRA DE ZOOTECNIA, 45., 2008, Lavras. Anais... Lavras: SBZ, 2008. CD-ROM.

9. HANISCH, A. L.; DALGALLO, D. Avaliação participativa de métodos de estabelecimento e épocas de plantio da grama perene Hemarthria altissima cv Flórida para o Planalto Norte Catarinesne In: REUNIÃO ANUAL DA SOCIEDADE BRASILEIRA DE ZOOTECNIA, 45., 2008, Lavras. Anais... Lavras: SBZ, 2008. CD-ROM.

10. OLIVEIRA, J. C. P.; MORAES, C. O. C. Distribuição da produção e qualidade de forragem de Bromus Auleticus Trinius. Pesquisa Agropecuária Brasileira, v. 28, n. 3, p. 391-398, 1993.

11. PEDREIRA, C. G. S.; PEDREIRA, B. C.; TONATO, F. Quantificação da massa e da produção de forragem em pastagens In: SIMPÓSIO SOBRE MANEJO DA PASTAGEM, 22., 2005, Piracicaba. Anais... Piracicaba: FEALQ, 2005. p. 195-216.

12. ROSA, J. L. et al. Forrageiras de clima temperado para o Estado de Santa Catarina. Florianópolis: EPAGRI, 2008. 64 p. (Boletim Técnico, 141).

13. SLEPER, D. A.; BUCKER, R. C. The fescues. In: BARNES, R. F.; MILLER, D. A.; NELSON, C. J. (Ed.) Forages. 5. ed. Ames: lowa State University Press, 1995. v. 1. p. 345-356.

14. SOCIEDADE BRASILEIRA DE CIÊNCIA DO SOLO. Manual de adubação e de calagem para os estados do Rio Grande do Sul e de Santa Catarina. 10. ed. Porto Alegre: SBCS/ Núcleo regional Sul; Comissão de Química e Fertilidade do Solo - RS/SC, 2004. 394 p.

15. SCHEFFER-BASSO, S. M. et al. Variabildade morfológica e agronômica em populações de Bromus auleticus (cevadilha vacariana). Biociências, v. 13, n. 1, p. 3-10, 2005. 
HANISCH, A.L. \& GISLON, I. Massa de forragem e valor nutritivo...

16. SCHEFFER-BASSO, S. M. et al. Comportamento de leguminosas (Adesmia, Lotus, Trifolium) em mistura com festuca. Revista Brasileira de Zootecnia, v. 31, n. 6, p. 2197-2203, 2002a.

17. SCHEFFER-BASSO, S. M.; SOARES, G. C.; DALL'AGNOLL, M. Efeito de freqüência e altura de corte em dois genótipos de Bromus auleticus Trin. Ex Nees. Revista Brasileira de Agrociência, v. 8, n. 3, p. 191-194, 2002b.

18. SILVA, D. J.; QUEIROZ, A. C. Análise de alimentos: métodos químicos e biológicos. Viçosa: UFV. 2002. 165 p.

19. YANAKA, F. Y. et al. Variabilidade genética em populações naturais de Bromus auleticus Trin. Ex Nees (Poaceae) com base em isoenzimas e marcadores RAPD. Revista Brasileira de Zootecnia, v. 34, n. 6, p. 1897-1904, 2005.

Recebido em 20/01/2009

Aceito em 15/10/2009 